ICTD Working Paper 128

Can Tax Agents Support Tax Compliance in Low-Income Countries? A Review of the Literature and some Preliminary Evidence from Uganda

Giovanni Occhiali and Fredrick Kalyango

October 2021 
Can Tax Agents Support Tax Compliance in Low-Income Countries? A Review of the Literature and some Preliminary Evidence from Uganda

Giovanni Occhiali and Fredrick Kalyango

ICTD WORKING PAPER 128

First published by the Institute of Development Studies in October 2021

(C) Institute of Development Studies 2021

ISBN: [978-1-78118-862-0]

DOI: $10.19088 /$ ICTD.2021.018

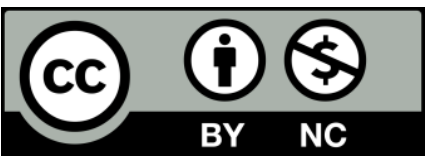

This is an Open Access paper distributed under the terms of the Creative Commons Attribution Non Commercial 4.0

International license, which permits downloading and sharing provided the original authors and source are credited - but the work is not used for commercial purposes. http://creativecommons.org/licenses/by-nc/4.0/legalcode

Available from:

The International Centre for Tax and Development at the Institute of Development Studies, Brighton BN1 9RE, UK

Tel: +44 (0) 1273606261

Email: info@ictd.ac

Web: www.ictd.ac/publication

Twitter: @ICTDTax

Facebook: www.facebook.com/ICTDtax

IDS is a charitable company limited by guarantee and registered in England

Charity Registration Number 306371

Charitable Company Number 877338 


\title{
Can Tax Agents Support Tax Compliance in Low-Income Countries? A Review of the Literature and some Preliminary Evidence from Uganda
}

\author{
Giovanni Occhiali and Fredrick Kalyango
}

\section{Summary}

Over the last 40 years there has been an increased focus on the role that tax agents play in ensuring or deterring compliance with tax obligations. While the literature on their role is not extensive, a variety of different topics have been explored. Some consistent evidence has emerged indicating when agents improve (or decrease) compliance, as well as the key drivers of their use by taxpayers. However, virtually all existing studies have focused on highor upper-middle-income countries. Given that the tax systems of low-income countries present a unique set of compliance issues, a more in-depth analysis of the role that tax agents might play in these contexts is warranted. In this paper, we provide an extensive review of existing literature on tax agents, and present some preliminary evidence from two surveys on their use in Uganda. Our results show that tax agents seem to contribute to an improvement in the quality of filed returns and to lower audit adjustments, hence supporting improved compliance. The type of services more frequently requested by taxpayers seem to match those in high-income countries, as do their reasons for engaging tax agents in the first place.

Keywords: tax agents; tax compliance; Uganda; low-income countries.

Giovanni Occhiali is a Research Fellow at the International Centre for Tax and Development (ICTD), where he works on different projects related to Tax Administration and Compliance, as well as co-leading ICTD capacity-building activities. His work focuses on sub-Saharan Africa. Outside the field of taxation his main interests are environmental and industrial economics.

Fredrick Kalyango is a tax practitioner with over 15 years of experience in tax administration. He is currently working as an Ag. Manager of Quality Assurance in the Domestic Taxes Department, Business Policy Division of the Uganda Revenue Authority. He is a Chartered Accountant and Chartered Tax Advisor of the Institute of Certified Public Accountants of Uganda (ICPAU). 


\section{Contents}

Summary 3

Acknowledgements 5

Acronyms $\quad 5$

$1 \quad$ Introduction $\quad 6$

$2 \quad$ Literature review $\quad 8$

2.1 Why taxpayers hire tax agents and the role of tax agents in
compliance -1984 to 1992

2.2 The 1990s - consolidation of the early evidence 10

2.3 The Australian experience - the early 2000s 11

2.4 The 2008 financial crisis and recent literature 13

$\begin{array}{ll}2.5 & \text { Literature summary } \\ & 14\end{array}$

3 Domestic resource mobilisation and compliance issues in Uganda 16

$4 \quad$ Current regulation of tax agents in Uganda and its potential weaknesses 17

$5 \quad$ URA tax officer and tax agent survey results 19

5.1 Survey of URA tax officers 20

5.2 Survey of tax agents 22

6 Conclusion $\quad 25$

$\begin{array}{ll}\text { References } & 28\end{array}$

Tables

Table 1

Table 2

Table 3

Table 4

Table 5

Table 6

Table 7

Assigned office of URA respondents 21

URA staff opinion on tax agent and taxpayer knowledge $\quad 21$

Size of client of tax agents 23

Frequency of service provision, ranked answers $\quad 24$

Frequently requested services, unranked answers $\quad 24$

Frequency of reasons for being hired, ranked answers 24

Frequent reasons for being hired, unranked answers 25 


\section{Acknowledgements}

Fredrick Kalyango would like to express his gratitude to the management of the URA and ICTD for giving him the opportunity to attend the 'Tax policy and Research Methods' training programme, through which this project was conceived. He would like to thank his wife Victoria Kalyango and his family for standing by him all the time, as well as his co-workers of the URA for their kind co-operation and their encouragement, which helped him to complete this project. Giovanni Occhiali would also like to thank the management of the URA for the access provided and the short notice with which they allowed one of the two surveys to be implemented. Both authors are grateful to two anonymous referees, whose comments greatly helped to improve the paper.

\section{Acronyms}

CPA Certified public accountant

HIC High-income country

ICPAU Institute of Certified Public Accountants of Uganda

IRS Internal Revenue Service

LIC Low-income country

SARS South African Revenue Service

TARC Tax Agents Registration Committee

TIN Taxpayer identification number

URA Uganda Revenue Authority 


\section{Introduction}

Since the late 1970s, many countries have based their tax systems on self-assessment taxpayers are expected to evaluate their liabilities autonomously, and voluntarily remit their tax due. If the tax system is perceived as fair and easy to navigate, with credible threat of penalisation for non-compliance, self-assessment reduces the cost of tax administration without significant revenue losses (Barr et al. 1977; Teviotdale and Thompson 1999; James and Alley 2004). On the other hand, self-assessment entails an increase in compliance costs for taxpayers, at the very least in terms of time spent complying with their obligations. However, none of the conditions mentioned above - fairness, simplicity and credibility - is easy to meet. Hence, initial moves towards self-assessment were met in many countries with an increased focus on what type of deterrence measures would increase taxpayer compliance (Forest and Sheffrin 2002), following the prevalent theoretical approach of the time (Allingham and Sandmo 1972). By the late 1990s, the focus was shifting to the perceived fairness and complexity of the tax system, increasingly seen as both a direct and indirect obstacle to compliance (Slemrod and Venkatesh 2002; Forest and Sheffrin 2002; Eichfelder and Schorn 2012). Intuitively, a taxpayer who does not understand their tax obligations has a hard time complying with them, and might well decide not to try at all especially if penalisation is seen as unlikely.

A potential solution for taxpayers who are struggling to understand their tax obligations, but intend to comply with them, is to hire a tax agent. ${ }^{1}$ This seems to have quickly become common: some of the first studies addressing issues of compliance costs with income tax in the United States found evidence that almost half of all taxpayers analysed hired a tax agent to prepare their tax return (Slemrod and Sorum 1984; Slemrod 1989). As the relevance of professional tax preparation in the US became more evident, some academics started studying the determinants of use of tax agents (Long and Caudill 1987), as well as the role they could play in either promoting or deterring compliance (Kaplan et al. 1988; Klepper and Nagin 1989). Despite the potentially important function that tax agents play in various countries, the study of their role within a tax system never gained much traction. Some further interest came in the late 2000s, as aggressive tax planning, usually involving tax agents, was seen as depriving countries of the revenue needed to pay for the financial crisis (OECD 2008). However, even in this case interest was short-lived. A recent review of research on tax compliance issues by one of the leading academics in the sector pointed out that the role of tax agents is still under-researched, and more empirical investigation is required (Slemrod 2019).

Most of the scant evidence on the role of tax agents comes from high-income countries (HICs), especially the US and Australia. There are only a few studies considering their role in a couple of upper-middle-income countries - South Africa (Lubbe and Nienaber 2012), and Malaysia (Isa et al. 2014; Sapiei and Kasipillai 2014; Sinnasamy et al. 2015). However, there is no reason to assume that tax agents could not be playing an important, if maybe different, role in taxpayer compliance in lower-middle- or low-income countries. Early research on the role of tax agents focused on their use by small and medium businesses (Hite et al. 1992), which are usually the majority of registered taxpayers in low-income countries (LICs) as well as HICs. Furthermore, while personal income taxes are currently paid by only a small fraction of the population in LICs, and account for a low proportion of revenue raised (Moore and Prichard 2017), this might be slowly changing. The recent focus of some revenue administrations in LICs on the taxation of high net worth individuals (Kangave et al. 2016;

Throughout the paper we use the term 'tax agents'. as this is more often used in Uganda. However, tax professionals, tax preparers and tax consultants are also fairly common in the literature. 
Kangave et al. 2018; Kangave et al. 2020), with more starting to consider a similar strategy, might soon lead to a greater use of tax agents by private individuals. Finally, recent work in the US has highlighted the role that tax agents can play in increasing their clients' knowledge of the tax system (Chetty and Saez 2013). Given how important outreach to taxpayers has become for revenue administrations in many LICs, it is important to understand whether LICs might try to pursue similar strategies.

Against this background, this paper presents some initial evidence on the use and regulation of tax agents in Uganda. This is an interesting case study for three main reasons. First, a recent study found that the high level of duplication of contact information in the taxpayer registry is due to the widespread practice of tax agents giving their own contact information when assisting with business registration (Mayega et al. 2019). Second, the Uganda Revenue Authority (URA) was one of the first African revenue authorities to engage with the taxation of high net worth individuals. After impressive initial results (Kangave et al. 2016), revenue accruing from this category of taxpayers has plateaued. While there is currently little evidence on why this is the case, one plausible reason might be an increase in tax planning, implying a higher involvement of tax professionals. Finally, many Ugandan taxpayers, and especially individuals, find it extremely difficult to comply with their filing obligations, and to interact with the URA to either amend their return or appeal against objections (Waiswa et al. 2020). The literature shows that these activities often lead taxpayers to hire the services of a tax agent (Long and Caudill 1987).

We conducted two separate self-administered surveys to provide some initial evidence on the role that tax agents play in Uganda. The first targeted URA tax officials, to get a better understanding of the interaction between tax officers and tax agents. The second covered tax agents, in order to gather information about their professional status, client base and the type of services they most regularly provide. These surveys are complemented by in-depth interviews with various members of the URA Tax Agents Registration Committee secretariat, which oversees the accreditation of tax professionals by the revenue authority. Our results suggest that, in line with the experience of HICs, various categories of taxpayers rely on tax agents to ensure that they are complying with their tax obligations, which many find difficult to understand. Reducing tax liability is mentioned, but seems to be less relevant in pushing taxpayers to look for the services of an agent. Both URA staff and tax agents confirm the relevance of their acting as intermediatries when taxpayers are asked to respond to queries from the URA. To the best of our knowledge, this is the first study to assess the role of tax agents in an LIC. While it is only a preliminary study, it already has some consequences for policy. First, it shows that tax authorities should give proper consideration to regulating the use of tax agents, to ensure they provide services of a high standard - which is in the interest of both the authorities and taxpayers. Second, it highlights that tax agents contribute to taxpayers' understanding of tax systems, and may be useful in outreach activities. Finally, given the demand to minimise tax due, it may be worth seeing tax agents as a useful intermediary with whom to share tax rulings and interact with on a regular basis to clarify any potential ambiguity in the tax code.

The rest of the paper proceeds as follows. Section 2 provides an extensive review of existing literature on the role of tax agents in high- and upper-middle-income countries. Section 3 discusses compliance issues in Uganda. Section 4 provides a brief overview of recent policies that the URA implemented to increase domestic revenue mobilisation and the role tax agents might play in them. Section 5 presents and discusses the results of the surveys, and section 6 concludes. 


\section{Literature review}

Given the widespread use of professional tax services, the academic literature on tax agents is not particularly extensive. The majority of studies reviewed come from the fields of economics and accountancy; a couple come from law. The following sections try to show how studying the role of tax agents in taxpayer compliance has evolved over time. There is more discussion of earlier studies, due to their role in influencing research theories and methods in this area. In subsequent sections, specific studies that either produced new evidence or relied on more interesting data sources are given more relevance.

\subsection{Why taxpayers hire tax agents and the role of tax agents in compliance - 1984 to 1992}

As mentioned earlier, findings from two studies conducted by Slemrod in the mid-1980s (Slemrod and Sorum 1984; Slemrod 1989) sparked initial interest in the effect that using tax agents had on compliance. The primary concern of both of these works was to assess how expensive it is for US taxpayers to comply with the personal income tax system, and how its simplification might affect these costs. Analysing 600 responses from randomly selected taxpayers from Minnesota, the authors found that 45.9 per cent used the service of a professional tax agent before submitting their returns (Slemrod and Sorum 1984). Not surprisingly, the agents' charges for preparing returns accounted for a significant proportion of the compliance cost. A potential reduction in their use could be a large proportion of possible long-term savings coming from simplification of the tax system (Slemrod 1989). Furthermore, their figure for use of agents closely matched that reported by the Internal Revenue System (IRS) for the 1979 round of their Taxpayers Compliance Measurement Program (44\%), proving that a significant use of agents had been a stable feature of the US tax system for a while.

While neither study directly intended to identify the reasons behind a decision to hire a tax agent, as a by-product of their analysis the authors provided a first account of taxpayer characteristics associated with their use. Again somewhat unsurprisingly, use of agents increased with taxpayer age, their marginal tax rate, their level of income, and when income from self-employment and capital gains were more relevant (Slemrod and Sorum 1984; Slemrod 1989).

The significance of all of these variables in determining which type of taxpayer was more likely to use tax agents was confirmed around the same period. Long and Caudill (1987) author the first study to address the question directly, employing a combination of logit, tobit and Heckman's selection models on more than 120,000 US personal income tax returns. The authors found that demographic characteristics relevant for taxpayers' qualification for particular deductions were only partially significant in explaining their decision to hire an agent. $^{2}$ Given the higher prevalence of the use of agents amongst taxpayers claiming itemised deductions, the authors conclude that it was the overall complexity of the return itself that motivated expenditure on a professional tax agent. Furthermore, the authors provide some initial evidence that, within the same income bracket, returns filed with support from tax agents are associated with lower liabilities than those self-filed for all but the highest and lowest income groups (Long and Caudill 1987).

Three other relevant studies were published in the late 1980s, all looking at one question strongly related to the above finding - how the use of tax agents affect taxpayer compliance.

For example, marital status, seniority and number of dependants. 
Two of them, Kaplan et al. (1988) and Ayres et al. (1989), share an approach that was to become a staple in the literature on tax agents - comparing the advice that different tax agents give when presented with hypothetical tax cases subjected to random variation. The last, Klepper and Nagin (1989), is based on aggregate information from 50,000 individual income tax returns from the 1982 round of the IRS Tax Compliance Measurement Program. Thanks to a more formal presentation of the theory behind impact of agents on compliance, this study was to have a stronger impact on the literature.

Kaplan et al. (1988) assess how the type and breadth of a tax agent's experiences might influence the advice that they provide to their clients in unambiguous and ambiguous tax matters. The authors hypothesise that previous experience should not have an impact on the type of advice that agents give on unambiguous tax matters. In this case the law offers a clear interpretation, and suggestions to clients should only be impacted by the probability of detection of non-compliance. On the other hand, the experience of tax agents should influence what they suggest in ambiguous cases. More experienced agents are more likely to have a standard position regarding ambiguous situations, developed through multiple interactions with the IRS. Conversely, less experienced tax agents will more often be guided by their clients' attitude to risk. Prior successful interactions with the IRS will also lead to more aggressive positions in both groups. To test these hypotheses, the authors submitted 4 theoretical tax scenarios to 52 tax agents with different levels of prior experience working for the biggest international accounting firms, randomly manipulating the probability of audit and the loss incurred if found in breach of the law. Relevant support was found for all the hypotheses. For unambiguous tax matters, all agents had a 'lottery' approach - they took a more aggressive position when probability of detection and penalties were lower, and level of experience did not play a significant role. In ambiguous situations, the probability of audit was only a significant predictor of aggressiveness with tax positions for less experienced tax agents. Finally, positive outcomes in previous tax rulings from the IRS led to more aggressiveness in both groups of agents. While the authors recognise both that the selection of tax agents was neither made at random nor necessarily representative, and that all hypothetical scenarios came from the same field, the results still highlight some plausible decision patterns.

In a related study, Ayres et al. (1989) compare tax advice between agents who are certified public accountants (CPA), and those without any professional affiliation. While CPA certification is not required to offer paid tax advice services, certified tax agents do have certain advantages. Due to IRS regulation, only agents qualified as certified accountants, lawyers, or those who have obtained official accreditation, have the right to represent their clients before the IRS. Furthermore, when a tax position is denied upon audit, as long as a CPA agent can demonstrate the existence of a substantial basis for it, penalties are usually waived, and their clients only pay the difference in assessed liabilities. These considerations led the authors to hypothesise that CPA agents would be more likely to take a pro-taxpayer position when reporting on ambiguous items than non-CPA agents. To test this, 168 agents with and without CPA affiliation were asked to declare which of the same set of 6 different suggestions they would give to their client for the same 5 different hypothetical tax scenarios. While the data provided strong support for their hypothesis, the authors also recognise that their results could have been driven by two factors they did not explicitly take into account. The first is a systematic difference in clientele types between CPA and non-affiliated agents; the second a systematic difference in level of prior training and experience. The latter might lead CPA agents to have a better feeling for what positions have a sound enough legal basis to be acceptable to the IRS. The former might imply that they usually deal with taxpayers that have a higher risk appetite to start with. 
The work presented in Klepper and Nagin (1989), while closely related to the above studies, takes a different and more data-driven approach. To start with, rather than leaving the distinction between ambiguous and unambiguous items to be intuitive, a formal ambiguity index was constructed. For each line item of a tax return, the index was obtained by combining the number of connected revenue rulings from the IRS with the relevance of monetary value imputed in its liability calculation (eg evaluation of loss due to theft, or in-kind charity donation). Secondly, instead of suggesting hypothetical scenarios, the impact of agents was calculated by comparing average voluntary reporting percentages for different classes of taxpayers. ${ }^{3}$ Finally, thanks to a specific outreach programme to increase compliance with expected personal income tax implemented in Pennsylvania in 1984, the authors were able to formally test if agents react to signals of increased attention on specific issues from the IRS. This hypothesis was verified by assessing the likelihood that taxpayers using agents would become first-time payers of that tax in that particular year. While admittedly very reliant on auditors' judgements, their analysis provided strong evidence that tax agents play a double role with regard to compliance. They increase taxpayer compliance with legislation whose interpretation is unambiguous or which is signalled as a priority by the revenue authority, while contemporaneously exploiting existing room to decrease clients' liabilities from sources whose legal treatment is ambiguous.

Hite et al. (1992) is the last study from the initial wave deserving extensive treatment, as it produced the first evidence on the reasons for small business owners to engage the services of a tax agent, as well as assessing the position they would like their agents to take on ambiguous items. Analysing 300 valid responses received from 1,500 small businesses contacted, the authors show that their first reason for engaging tax agents is to ensure that returns are correctly compiled, followed by reducing potential penalties, with tax minimisation only third on the list of priorities. While more than a third of respondents admitted to some form of non-compliance in the past, this does not seem to correspond to an appetite for aggressive declarations of ambiguous sources. In fact, business owners were happy for their agents to minimise liabilities on dubious items only when they had a 70 per cent confidence that the IRS would agree with such a position. Furthermore, the majority of respondents wanted to be in control of the final decision on what to declare on ambiguous items, with no evidence of correlation between the said preference and appetite for aggressive reporting or prior non-compliance.

Several important elements of the role of tax agents in the US tax system started to be determined through this first wave of studies. By the early 1990s, it was clear that the use of agents had been widespread for over a decade, with important consequences on the cost of taxpayer compliance. While the use of agents was common across all categories of taxpayers, it rose with their income level and with the complexity of their tax return, which was in part associated with their sources of income. The use of agents was associated with higher compliance on unambiguous tax rules, and more aggressive tax reporting on ambiguous ones. Both of these decisions were influenced by agents' experience in dealing with the IRS, and, relatedly, by their professional qualification in what already appeared a segmented market. However, it also seemed that, at least amongst certain taxpayer categories, willingness to be compliant with the tax system and to avoid penalties was a much more important reason to engage their services than minimising tax liability.

\subsection{The 1990s - consolidation of the early evidence}

Much of the work on tax agents during the 1990s aimed to refine initial findings on their role, using similar methods and data. Evidence showed that the effort to simplify the US tax

\footnotetext{
This is defined as the ratio between liabilities voluntarily disclosed and those assessed by the auditors through the
} Taxpayers Compliance Measurement Program. 
system and reduce compliance cost in the mid-1980s did not lead to the expected long-run decrease in use of agents (Blumenthal and Slemrod 1992). Other studies show that highincome taxpayers are more likely to engage tax agents to exploit ambiguity in tax legislation (Klepper et al. 1991). Credible threat of sanctions from the tax authority on agents was demonstrated to reduce their willingness to sign returns with aggressive deductions (Newberry et al. 1993), with an appetite for the latter seemingly connected with taxpayers' positive liabilities after withholding tax (Schisler 1994). Others showed that particular taxpayer characteristics are significant predictors of use of a CPA agent, while also demonstrating how this category of agent leads to much higher non-compliance on ambiguous items than those without an explicit professional affiliation (Erard 1993).

Further support for the claim that ensuring compliance with obligations prevails as a reason to engage tax agents came from New Zealand, where a researcher surveyed close to 700 taxpayers, predominantly small business owners (Tan 1999). Using the 'hypothetical tax scenario' approach, their results showed that if there were serious disagreements on reporting positions, taxpayers would have no qualms in terminating the relationship with their tax agent. Somehow surprisingly, the same preference for conservative tax advice was reported in a large survey of Australian taxpayers who had been involved in different massmarketed tax planning schemes, popular in the country during the 1990s (Murphy and Byng 2002). Some work started investigating potential discrepancies between what taxpayers expected to receive from their tax agents, and what the latter imagined the main focus of their clients to be (Christensen 1992). The effect of confirmation bias on the ability of tax agents to assess the validity of their positions on ambiguous items also received some attention (Cloyd and Spilker 1999).

As more evidence started accumulating on the heterogeneity of the impact of agents across their different qualifications, some authors explicitly considered the role that state regulation of tax professionals could play. Assessing the experience of various countries, Thuronyi and Vanistendael (1996) argue that regulation should strive to find the appropriate balance between ensuring the loyalty of tax agents towards the general tax system, and towards their client. Protecting the latter from receiving bad service - a theme previously covered with specific reference to the US system in the late 1980s (Jackson et al. 1988; Jackson and Milliron 1989) - was seen as one of the main aims of regulation. No single approach seemed to have prevailed across the countries considered, as there were a variety of different professional figures providing tax services, many of which had their own regulatory body. Although usually accountants, auditors and lawyers worked as tax agents in the countries studied, the nature of the tax services they provided varied greatly depending on the tax system. The authors also consider what type of regulation could better fit transition economies, concluding that a simple definition of the right of taxpayers to use a representative, as well as the consequences of such a decision, was probably all that was required, given how little depth there was likely to be to the tax service markets.

\subsection{The Australian experience - the early 2000s}

The most interesting studies on the role of tax agents within a tax system in the early $2000 \mathrm{~s}$ came from Australia, where in 1998 the Australian Taxation Office (ATO) decided to legally pursue tens of thousands of taxpayers that had become involved in tax planning schemes during the 1990s. Initial resistance by taxpayers to the ATO request to pay significant arrears led to a surge in interest in the topic of tax compliance, and a few large surveys were published (Braithwaite 2001; Murphy 2002; Murphy and Byng 2002). A study relying on one such survey, Niemirowski et al. (2003), aims to acquire a general understanding of compliance behaviour among Australian taxpayers, as well as their attitude towards, and beliefs about, the tax system. The authors ran an extensive survey covering more than 1,000 
taxpayers across different risk profiles, matching survey responses with actual returns, as well as sampling more than 300 Australian Tax Officers and 60 tax agents. Results from the latter group revealed how Australian tax agents felt that their clients delegated the 'moral responsibility' of finding the right amount of minimisation to them, hence maintaining the high ground towards the acceptability of tax avoidance schemes. Agents generally held very strong views about the seriousness of tax evasion, while also representing the only group tolerating a high level of tax avoidance. This tolerance was connected to the perception that the tax system did not ensure fair treatment of all taxpayers, so tax planning was the only way to ensure that some clients had enough funds for retirement. The vast majority also agreed that their clients would lie about tax matters, and approximately half reported having been threatened with dismissal if they did not followed their clients' exact instructions. As a consequence, most agents felt that they could perceive which of their clients were likely to incur reporting issues, and over half of them had previously decided to stop providing services to particular clients.

Another survey from the same period targeted close to 8,000 randomly selected Australian taxpayers, asking a variety of questions related to their tax knowledge, perception of the tax system and relationship with tax professionals. While only about 2,000 responses were received ( $29 \%$ of the targeted sample), the overall distribution of respondents' characteristics seemed to be representative of the overall population (Mearns and Braithwaite 2001). Two studies used this data to investigate different aspects of the relationship between taxpayers and tax agents. The first, conducted by one of the survey's authors, aimed to provide more evidence for the hypothesis that tax agents work in a segmented market, and to assess how easily taxpayers can find the type of agents they are looking for (Sakurai and Braithwaite 2003). Apart from confirming that the vast majority of respondents used a tax agent $(77 \%)$, their study supported the finding that most taxpayers have a preference for agents taking low risk positions, minimising liabilities when it is safe to do so. However, there also exists a significant minority (26.42\%) who actively look for agents versed in aggressive tax planning and are capable of building complex tax minimisation strategies, with an understanding that this might make conflict with the tax authority more likely. ${ }^{4}$ Generally, it also seems that a majority of respondents could find a tax agent matching their preferred approach to tax reporting. The second study, Murphy (2003), focused explicitly on the minority of respondents who stated a preference for a tax agent versed in creative accounting, trying to ascertain if they shared some common characteristics. The analysis revealed that the majority of them are younger, less educated and earning more than the average survey respondents. Unsurprisingly, they also have a generally lax attitude towards tax compliance - not only thinking that there is nothing wrong with tax evasion, but that it is actually the smart thing to do.

The role that regulation might play in ensuring minimum technical and ethical standards was also studied - an extensive modification of the Australian tax agents' code, aimed at curbing the proliferation of tax minimisation schemes, was at the time under discussion. To better understand the effect that regulatory requirements played in the agents' market, McKerchar et al. (2008) exploit the difference between the strict regulation in the state of Oregon and the much laxer one in the rest of the US. While the authors recognise that US tax agents are not necessarily representative of their Australian counterparts, no data was available to explore this relationship within Australia. Assessing potential discrepancies across different income sources, calculation errors and audit results across the two geographical groups, the authors conclude that higher qualification requirements for tax agents are associated with higher

While there are known issues with self-reported answers about potentially sensitive topics, the fact that more than a quarter of respondents expressed a preference for aggressive tax planning seems to indicate a certain degree of openness with regard to this tax attitude in Australia. 
voluntary disclosure rates and more accurate returns. These findings indicate that the Australian reform was probably moving in the right direction.

This second wave of studies coming out of Australia expanded the body of evidence that had emerged in the US over the previous two decades, showing that many of the original results were holding in a country that has both similarities and differences. Even in the Australian context, the use of tax agents is widespread amongst taxpayers (Mearns and Braithwaite 2001), and the vast majority of them are mainly looking to ensure that their return is correct and prefer a more conservative position. Some tax minimisation was often requested, but only a minority of taxpayers were actively looking to exploit as many grey areas as possible (Sakurai and Braithwaite 2003). While this category could find tax agents willing to support them (Murphy 2003), the majority of the profession preferred to avoid engaging with clients who were likely to be found in non-compliant positions (Niemirowski et al. 2003). Over this period, more research on the discrepancy between taxpayers' motivation to hire agents and the latters' perception of the services requested from them also took place in the US, but did not add anything substantially novel to the literature (Stephenson 2007, 2010).

\subsection{The 2008 financial crisis and recent literature}

The topic of professional tax services has received increasing attention during the last decade due to growing awareness of the detrimental impact of transfer pricing and other international tax planning schemes. An OECD study on the role of tax agents in aggressive tax planning concludes that these activities are usually demand-led, and that the vast majority of big corporate taxpayers have enough in-house capacity to set their own tax strategy without consulting external tax agents (OECD 2008). Subsequently, information leaks, such as the 'Panama papers' in 2016 and 'Paradise papers' in 2017, and the clear indication of the role that various types of tax agents played, once again convinced some authorities that more regulation of tax advisory services was required (Roxan et al. 2017). In 2017 the EU adopted a specific legislation, implemented in the summer of 2020, obliging all tax intermediaries to declare all cross-border tax arrangements within its border (Remeur 2018).

While some studies in this period continued developing the same themes of the previous literature, others started exploring new directions. In the first group, authors focused on different perception of priorities between agents and clients (Fleischman and Stephenson 2012; Tan 2014; Stephenson et al. 2017), or on determinants of client satisfaction with the services received (Gupta 2015; Frecknall-Hughes and Moizer 2015). In the second, they drew bridges between competing theoretical approaches on the practice of tax agents, looking for a unifying theory (Frecknall-Hughes and Kirchler 2015), or focusing on the lobbying power of in-house tax agents of digital multinational corporations and their capacity to strongly influence regulation of their sectors (Mulligan and Oats 2016). The interaction between corporate actors, tax agents and tax authorities was also the explicit focus of a study providing critical insights into how tax knowledge is created, shared and implemented in the UK (Hasseldine et al. 2011). The authors support the view that it is in the best interest of tax agents to be seen as reliable partners by both their corporate clients and HMRC, as this allows them to play both the role of enforcer and exploiter of rules. However, this also puts them in the spotlight of both corporate and institutional organisations, which perceive these conflicting roles and - especially from the corporate side - might fear that the knowledge flows between different links of this chain does not favour them.

More empirical work, combining administrative data with tax agent surveys, also emerged in the US. Two examples are worth mentioning. The first, Chetty and Saez (2013), focuses on the educational role of tax agents. The authors assess the impact of a short explanation of 
the mechanism behind the Earned Income Tax Credit - the largest cash transfer programme in the US - on labour supply decisions of half of 43,000 randomly selected clients of a large tax advisory firm. While they found that their treatment only had a marginal effect in incentivising clients towards the 'optimal' labour supply, there was evidence of heterogeneity of effects across different types of tax agents. This led them to hypothesise that supporting particular type of tax advisors could be a more effective way to increase the scheme's effectiveness than a blanket information campaign - while also further demonstrating that agents' characteristics matter for their impact, even within the same firm. The second study, Zwick (2018), explores if a difference in the quality of tax agents hired could explain the low take-up (37\%) of carry-back refunds in the US. ${ }^{5}$ By exploiting exogenous switches in tax agents to identify their impact on client behaviour, the author discovers that agent sophistication - measured by academic qualification and professional body affiliation - is a significant and consistent predictor of refund take-up, especially for small and medium firms.

We conclude the review with the limited number of studies assessing the role of tax agents in upper-middle-income countries rather than HICs, on which all of the prior literature was based. A few studies emerged in the early 2010 s to verify if some of the claims made about the role of tax agents in HICs could be valid for Malaysia, which moved to a self-assessment system in 2004. While not as technically advanced as other work from this period, these studies - which only focus on corporate taxpayers and their agents - provide suggestive evidence that the complexity of the Malaysian tax system was the main reason to employ a tax agent, although tax planning usually followed closely (Isa et al. 2014; Sapiei and Kasipillai 2014).

Lubbe and Nienaber (2012) provide the only example of a study from a country in the African continent, South Africa. In 2005, an amendment to the Revenue Law made it compulsory for all tax agents to register with the South African Revenue Service (SARS) and to seek accreditation with a soon-to-be-established professional body. While this led to almost 23,000 agents registering with SARS, the institution of their regulatory body, started in 2008 , had not been completed when the study took place. ${ }^{6}$ In the authors' opinion, this left room for potentially aggressive tax reporting to persist, as agents were not subjected to any explicit code of conduct. Given that SARS reported that in 2004 more than 90 per cent of small businesses outsourced completion of their tax returns, the authors decided to verify if this was mostly due to fear of penalties following a reporting error, or to a desire to minimise their tax bill. A replication of the experiment run by Tan (1999) with 50 business owners showed that, even in South Africa, obtaining an accurate return and minimising the probability of audit were more important reasons to seek the services of a tax agent than tax minimisation. However, despite the fact that the majority of respondents claimed to favour conservative advice, a choice-experiment revealed a preference for aggressive reporting on ambiguous items by the majority of respondents.

\subsection{Literature summary}

As the above review demonstrates, the role of tax agents within the tax system of a reduced number of HICs has drawn some attention for 40 years. However, over this period, only a limited number of topics have actively been investigated. Quite a few authors have tried to determine the main characteristics of taxpayers seeking to employ an agent, and the

\footnotetext{
These are refunds that can be claimed by applying current losses against previous taxable income.

The creation of a new professional body was dropped in 2013. It was instead decided that the Institute of Accounting and Commerce, the South African Institute of Chartered Secretaries and Administrators, the South African Institute of Chartered Accountants, the South African Institute of Professional Accountants and the South African Institute of Tax Practitioners would be the recognised controlling bodies. See https://www.gov.za/recognition-controlling-bodies-taxpractitioners.
} 
services most often requested. The use of agents seems to be pervasive in the US (Slemrod and Sorum 1984; Blumenthal and Slemrod 1992), New Zealand (Tan 1999), Australia (Mearns and Braithwaite 2001; Sakurai and Braithwaite 2003), and it has more recently been shown as relevant in South Africa (Lubbe and Nienaber 2012). The complexity of complying with tax legislation seems to be one of the main drivers for their employment (Long and Caudill 1987; Isa et al. 2014), and most taxpayers engaging their services seem to do so chiefly to ensure that they are compliant with their obligations (Hite et al. 1992; Tan 1999; Sakurai and Braithwaite 2003). However, there is also often a desire to reduce tax liabilities, although how aggressively depends on both geographical context (Hite et al. 1992; Sakurai and Braithwaite 2003; Lubbe and Nienaber 2012) and taxpayer characteristics (Klepper et al. 1991; Erard 1993; Schisler 1994; Murphy 2003).

The desire of taxpayers to both follow tax legislation and reduce their tax liability also led different authors to study the general impact of tax agents on taxpayer compliance. Since seminal work in the late 1980s, it has been established that agents indeed play a double role, increasing compliance with unambiguous legislation, but also exploiting ambiguous provisions to minimise their clients' liabilities (Kaplan et al. 1988; Ayres et al. 1988; Klepper and Nagin 1989). How successfully they defend their clients' interest in front of the tax authority seems to depend on their professional background, with lawyers and CPAs generally willing to take more risk when they feel that their position has a substantial basis (Kaplan et al. 1988; Ayres et al. 1989; Erard 1993). Professional qualifications and experience with particular categories of clients has also recently been shown to impact the capacity of agents to explain to their clients what could be in their best interest (Chetty and Saez 2013) and how to exploit lesser known tax provisions (Zwick 2018). Given the role of tax agents as knowledge intermediaries between tax authorities and taxpayers (Hasseldine et al. 2011) and their ability to lobby for favourable legislation in particular industries (Mulligan and Oats 2016), their professional regulation has also received some interest. While the professional background of a tax agent varies greatly across countries (Thuronyi and Vanistendael 1996), a balance has to be found on how strict entry requirements should be. While requiring a high academic qualification to enter the market increases accuracy of returns (McKerchar et al. 2008), the literature also shows that more qualified agents are more likely to take an aggressive position. Striking the right balance between a regulation ensuring taxpayer confidentiality and one that protects the integrity of the tax systems has also proven complex, and was until recently subject to some institutional scrutiny (Roxan et al. 2017; Remeur 2018).

From a methodological point of view, studies assessing the role of tax agents in the tax system have generally relied on a combination of different strategies. Those looking at taxpayer preferences for different types of agents have often based their results on mailed questionnaires (Slemrod and Sorum 1984; Slemrod 1989; Blumenthal and Slemrod 1992; Sakurai and Braithwaite 2003; Murphy 2003), which at the time included an experimental component (Hite et al. 1992; Tan 1999; Lubbe and Nienaber 2012), and in one case analysis of tax returns (Niemirowski et al. 2003). Studies that investigated what agent characteristics impact the type of advice provided have normally employed assessments of hypothetical tax scenarios subjected to some variation in probabilities of audits and penalties (Kaplan et al. 1988; Ayres et al. 1989; Schisler 1994), or on the analysis of unaudited (Long and Caudill 1987) and audited tax returns (Klepper and Nagin 1989; Klepper et al. 1991; Erard 1993; McKerchar et al. 2008). More recent studies have been set up in an experimental framework, either as randomised controlled trials (Chetty and Saez 2013), or as natural experiments (Zwick 2018). 


\section{Domestic resource mobilisation and compliance issues in Uganda}

In this section, we briefly present the current domestic resource mobilisation context in Uganda, highlighting some compliance issues that the URA still faces, while drawing from the previous review to see what role tax agents might play in reducing or exacerbating these issues. The tax-to-GDP ratio in Uganda has increased by 2.8 percentage points between 2014 and 2019, reaching 12.5 per cent in 2019 - enough to cover 44 per cent of the national budget (MOFPED 2019). Collection was close to - but never reached - what was targeted for every year between 2016 and 2018, with the under-performance mostly concentrated in domestic taxes. There have long been suspicions of widespread evasion and noncompliance with tax obligations in the country, especially for those income taxes where liabilities are determined uniquely through self-assessment. Both corporate and personal income taxes account for a relatively low share of total revenue collection -6 per cent the former and 17 per cent the latter - especially when compared with their average contribution in other East African countries (Waiswa et al. 2020).

Many reasons have been mentioned for this non-compliance, ranging from lack of adequately trained personnel at the URA to the existence of an extensive informal sector, ${ }^{7}$ from poor bookkeeping practices by the majority of businesses to the complexity of the tax system. Especially the latter seems to play a significant role. A recent study reports that a significant share of taxpayers find both filing and amending returns, as well as responding to queries from the URA and appealing its decision, extremely complicated (Waiswa et al. 2020). Various URA annual reports between 2016 and 2019 identify the low quality and inaccuracy of returns submitted as a serious threat to revenue collection, for which urgent action was needed. It is fairly likely that the complexity of both the tax legislation and the return form could be two of the reasons.

Waiswa et al. (2020) report that paying taxes and registering for a taxpayer identification number (TIN) were the only two activities which taxpayers found easy to execute. However, other recent work in the country highlights serious issues with the information that taxpayers provide at the point of registration (Mayega et al. 2019). The authors of the study discover very frequent duplication of both email and telephone numbers for a variety of taxpayers, and infer that this is due to tax agents providing their own details instead of their client's at the moment of registration. The authors believe this practice arises both because of a requirement to provide an email address to register, which many taxpayers might not have, and tax agents wanting to keep control over their client's return in order to demand more frequent payment.

Given these issues, it is not surprising that the URA has over the years stepped up its work to facilitate tax compliance, recognising that tax authorities have to see themselves as service providers. This has taken a variety of different forms:

- many tax services have been automated, reducing the need to travel to tax offices;

- taxpayer education campaigns, aiming to clarify tax obligations, have been frequent and used different media, targeting different stakeholders;

While the existence of an extensive informal sector does pose important challenges to a tax system, it is also important to recognise that the potential revenue contribution of many informal businesses is likely to be minimal or inexistent. For a recent discussion of the focus of many African revenue authorities on registering informal businesses, see Moore (2020). 
- the number of tax offices has increased, to facilitate access in more remote areas of the country; and

- welfare improvement programmes have been directed to URA staff, to improve morale and the quality of services provided.

While all these activities have helped increase voluntary compliance, there is scope to continue improving them (Waiswa et al. 2020).

However, most attention should be directed towards improving enforcement action- the other half of compliance improvement strategies, which is recognised to be a real weak point for the URA (Waiswa et al. 2020). Existing evidence points towards a variety of different areas in need of more attention. Between 2014 and 2018 the URA completed approximately 10,000 audits from a population of over 1.5 million taxpayers, more than half of which are classified as inactive (Mayega et al. 2019). Some focus should be dedicated to understanding which of the many inactive taxpayers are worth chasing, and which should simply be deregistered as they will be unlikely to ever have a positive liability. It also remains particularly hard to access taxpayers' information from third parties, especially from land registry, utilities and commercial banks (MOFPED 2019). Initial attempts to obtain access to citizens banking data were blocked due to popular and high-level political resistance, as the URA's right to access relevant banking information, granted under the Income Tax Act, was deemed weaker than Bank of Uganda guidelines on consumer protection. Similar political interference has also materialised against attempts to recover tax arrears (Waiswa et al. 2020). Enforcement actions are also made more complex by the general understaffing of the URA, which has a taxpayer-to-tax-administrator ratio around three times higher than other African countries (Waiswa et al. 2020). It is also generally perceived that not enough attention is directed towards compliance from small businesses, as they are often thought not worth the effort of a close follow-up. While this might be the case for some businesses added in the most recent registration drives, and is understandable given current understaffing, it risks having serious consequences to the integrity of the tax system (Waiswa et al. 2020).

In this situation, is there any theoretical or empirical evidence that focusing on the role of tax agents might facilitate the resolution of some of these issues, or provide the URA with further avenues to improve programmes on which it has already focused? A few things emerge from the review in the previous section. First, there is evidence that the URA could engage with tax agents for sensitisation drives directed towards taxpayers. They have proved to be more effective than general information campaigns in other contexts (Chetty and Saez 2013), and their role as information brokers is well recognised (OECD 2008; Hasseldine et al. 2011). Secondly, working in conjunction with tax agents could simplify ensuring compliance with small businesses. Evidence from a few different HICs indicates that this taxpayer category has a preference for conservative advice (Hite et al. 1992; Tan 1999) and for ensuring that their returns are correctly compiled (Hite et al. 1992; Tan 1999; Stephenson 2007, 2010; Lubbe and Nienaber 2012). Imposing strict requirements for qualification as a tax agent could also play a role in improving the quality of returns (McKerchar et al. 2008). However, too stringent a regulation might increase the number of taxpayers accessing services of agents who are confident in providing more aggressive advice (Ayres et al. 1989; Erard 1993). 


\section{Current regulation of tax agents in Uganda and its potential weaknesses}

First, it is worth noting that during the course of this study - and partially due to its role in making the issue more prominent within the URA - a series of efforts have been made to implement tax agent regulation that already existed in the country more fully, as well as making some partial amendments. According to Ugandan law, a tax agent is 'a person engaged inter alia, in preparation, certification, and filing of tax returns, information returns, or other statements or reports required by the URA, on behalf of the taxpayer' (Tax Procedures Code Act 2014). In order to regulate the conduct of tax agents and enhance the accuracy of tax returns filed by taxpayers, the Tax Procedures Code Act also mandated that tax agents who assist taxpayers in preparing tax returns be vetted and accredited by the Tax Agents Registration Committee (TARC). The requirement for registration as a tax agent is completion of tertiary education in a 'discipline which is relevant for the provision of tax services', the successful completion 'of a course in taxation recognised by TARC', or having had two years of 'full time tax-practice' experience during the five years preceding the coming into force of the act (Tax Procedures Code Act 2014). The Act does not specify what the relevant disciplines are, what type of courses have to be recognised by TARC, nor what is intended by 'full time tax practice', and no practice note has ever been directed to the issue. Work on the effect of regulation of agents stressed that very stringent entry requirements might lead to an increase in aggressive tax advice (Ayres et al. 1989; Erard 1993), but that some minimum standards are required to improve the quality of returns (McKerchar et al. 2008). It is not exactly clear where in the spectrum the current requirements lie, but it seems more likely that they might fail to improve quality rather than increase aggressiveness of tax reporting.

The Tax Procedures Code Act only came into force in July 2016 following the promulgation of a dedicated statutory instrument by the Minister of Finance; it took more time to appoint the member of the TARC, which was inaugurated in May 2017. The registration of the first tax agents, requiring an initial non-refundable payment of USh200,000,8 followed by a further USh500,000 upon approval, started soon afterwards. By the end of December 2017289 agents had been accredited to practice the following year. Due to the novelty of the process, both the submission and the vetting of documents required for accreditation was done manually. This proved to be particularly cumbersome, and partially explains why the number of tax agents approved for 2019 decreased to 231. To overcome this issue, over the course of 2019 both the tax agents' application process and their nomination by taxpayers were automated within e-Tax, ${ }^{9}$ with the aim of greatly simplifying both. However, different IT challenges on the URA side led to the opposite result: only 34 taxpayers managed to nominate tax agents, and the accreditation process was so disrupted that it had to be suspended altogether. ${ }^{10}$ As a consequence, no tax agent was accredited for 2020 - all applications were carried forward for consideration over the following year, and all of those who applied where automatically granted the permit to operate as agents.

In-depth interviews with three members of TARC conducted in early 2020 revealed they are all strongly convinced about the usefulness of the current URA policy, although they would

\footnotetext{
The exchange rate in 2017 was US\$1 = UGSh3,611 (World Bank Development Indicators). e-Tax is the integrated tax administration system currently in use in Uganda.

These IT failures also made it impossible to rely on the e-Tax system to obtain data for this research, as only 34 taxpayers had nominated their agents before nominations were suspended. It must be noted that the current set-up of e-Tax does not explicitly distinguish between returns submitted by agents and those submitted by taxpayers, as the former are allowed to file using the latter's TIN. While this issue is currently being addressed, it meant we could not proceed with any quantitative comparison of the impact of agents on the quality of returns.
} 
appreciate stricter enforcement, as well as some revision, of the current regulation. Their positive view of the policy is due to it being more cost-effective to engage with a small group of agents than with the large number of taxpayers who rely on their services. If the regulation were fully implemented, the overall effect would be positive for both taxpayers and the URA the former would be more confident about engaging a professional whose expertise had been vetted, and the latter would receive returns of a higher quality.

However, they also generally take issue with current management of the registration and nomination process. Apart from recognising the impact that the glitches in the IT system had on taxpayers' capacity to nominate agents, their biggest problem is with the vetting process and qualification requirements. This is because the process of verifying information submitted by agents with various vetting bodies is lengthy when they are based in Uganda, and very challenging to bring to completion when they are based outside it. Other issues mentioned are availability of information on criminal backgrounds from Ugandan law enforcement agencies, as well as the complexity of verifying agents' previous work experience as they previously operated in an unregulated environment. Furthermore, they have also realised that even when tax agents meet all the necessary requirements and possess the right academic qualifications, this is no guarantee that they will have the actual skills required for the work, since there is no examination in order to become an agent.

Some also find other aspects of the Tax Procedure Code Act problematic. It requires all taxpayers with a turnover above USh500 million to have a financial statement audited by a member of the Institute of Certified Public Accountants of Uganda (ICPAU) accompanying their tax return. ${ }^{11}$ They believe that so far this provision has not had an impact on the quality of tax declarations, given that it is often not enforced. Even when it is, the URA does not have any control over the standard required to be a member of ICPAU. However, this was not a unified position within TARC. Other members suggested reviewing the current regulation and lowering the qualification requirement to include Accounting Technicians and Certified Tax Advisor trainees from ICPAU. Both of these are widely available, and should be capable of managing tax affairs with some further training. Hence, there seems to be some tension between different members on the current relationship between the URA and ICPAU, which might warrant further consideration for the future.

All interviewees were convinced of the usefulness of designing and offering regular training to tax agents, with the aim of understanding their challenges and increasing their competence. Another common recommendation was for the URA to push for an amendment of the law, to make it compulsory for an accountant signing a taxpayer's return to be their nominated - and registered - tax agent. They were also convinced that taxpayers above the USh500 million threshold who fail to nominate a tax agent in time should be heavily penalised, to potentially incentivise compliance with this rule.

\section{URA tax officer and tax agent survey results}

In this section, we present the results of two exploratory surveys aimed at acquiring some initial evidence on URA tax officers' perception of the role and quality of tax agents, and on the latter's perceptions of their relationship with their clients. One of the authors emailed the first survey to a sample of 158 URA tax officers, representative of the 321 compliance staff working at the URA headquarters in March 2020; 81 of these returned a completed questionnaire. The second was a self-administered questionnaire, which was completed by

11 The ICPAU is Uganda's regulatory body for accountants. 
204 tax agents who attended a series of workshops at the URA between the end of October and early November 2020. A couple of limitations in our data need to be discussed before looking at the results. First, both sets of questionnaires were self-administered, and there was no chance to look into in-depth explanation of each question and potential answers. Therefore, it might be that nuances between different multiple choice options - such as complexity of general tax obligations or complexity of the return form itself - might have been lost on responders. To this end, where appropriate, we aggregate answers together into one logical overarching category. Secondly, there were instances where, despite being requested to select only one answer, more than one was indicated. In these cases, only questionnaires where answers were given according to the instructions are reported. Third, two of the questions included in the tax agents' questionnaire asked them to provide an explicit ranking of different options - many respondents ignored this, simply ticking all that applied. For those answers, the ranked answers are reported separately from the unranked ones. Finally, we could not ensure that sampled individuals were representative of the whole population. As this study is intended to provide a first set of evidence and guide future work, these issues should not make the answers less indicative of general trends.

\subsection{Survey of URA tax officers}

As seen in Table.1, respondents from the URA came from all the different departments that manage taxpayer compliance. The majority of those who returned a completed questionnaire worked in offices that only deal with taxpayers after they have filed a return - all but the respondents from the Medium and the Large Taxpayer Offices. With the originally sampled respondents, there is a higher representation of officers managing large taxpayers $(29.6 \%$ of respondents vs. $18.9 \%$ of the sample), and a lower representation of those working on revenue assurance (23.5\% of respondents vs. $34.8 \%$ of the sample). ${ }^{12}$ Consequently, if the views amongst these two categories are significantly different, our results will be unrepresentative of the URA position. However, the only two variables for which response patterns are significantly different are those on frequency of tax agent use amongst taxpayers and tax agents' knowledge. Unsurprisingly, tax officers from the Large Taxpayer Office are both more likely to state that most of their clients use a tax agent, and that tax agents are knowledgeable or very knowledgeable about the tax system. Therefore, with this caveat in mind, the following responses should still provide a fair representation of the opinion of tax officers of tax agents.

It might also be reasonable to assume that perceptions of the role and capacity of tax agents differ between officers dealing with taxpayers before their returns are submitted, and those dealing with them afterwards. Hence, a test of systematic differences in response across these two categories was performed for most of the questions in the survey. ${ }^{13}$ Comments will mostly be made when these differences are significant. Officers from the Medium and Large Taxpayer Offices will be referred to as 'pre-filing', the others as 'post-filing'.

The average difference between sample and respondents for all other categories of respondents is $3.7 \%$.

As all responses to questions in these section are from categorical or ordinal variables, systematic differences for the latter have been verified with Mann-Whitney $\mathrm{U}$ test, and for the former through Fisher's exact test. 
Table 1 Assigned office of URA respondents

\begin{tabular}{|l|ll|}
\hline & Frequency & Percentage \\
\hline Large Taxpayers Office & 24 & 29.63 \\
Medium Taxpayers Office & 7 & 8.64 \\
Objection and Appeals Office & 5 & 6.17 \\
Refunds Office & 13 & 16.05 \\
Revenue Assurance Office & 19 & 23.46 \\
Tax Examination Office & 13 & 16.05 \\
\hline \hline Total & 81 & 100 \\
\hline
\end{tabular}

Given that the use of tax agents is in no way mandatory, it is not surprising to find almost the totality (93.8\%) of URA staff surveyed agree that there are taxpayers who are not using their services. However, the majority of tax officers surveyed (64.2\%) state that most of the taxpayers they handle use a tax agent. As there is no difference in the pattern of responses between staff in pre- and post-filing offices, this phenomenon seems to be widespread. When asked about the timeliness of declarations and the quality of returns from taxpayers who take care of their tax obligation autonomously, the majority of URA staff find them to be on average with the general taxpayer population. However, opinions about timeliness significantly differ between staff in pre- and post-filing offices, with those working in post-filing stating that taxpayers with agents are less likely to be on time. When directly asked if the use of tax agents makes it more likely that returns will be filed late, 40.5 per cent of respondents either disagreed or strongly disagreed, about the same as those who either agreed or strongly agreed with it (36.7\%).

Unsurprisingly, when staff are asked to express a judgement on tax knowledge of both tax agents and taxpayers, measured on a 4-point Likert scale, tax agents are twice as likely to be considered 'Knowledgeable' or 'Very knowledgeable' - the upper half of the scale - as taxpayers. However, two things must also be noted. First, 55.6 per cent of URA staff still rate tax agents' knowledge in the lower half of the scale. Second, staff in post-filing offices are significantly more likely to have a low opinion of tax agents' knowledge than those in prefiling offices. This seems to indicate that, similarly to the TARC interviewees, URA staff have a mixed opinion on the level of preparation of tax agents.

Table 2 URA staff opinion on tax agent and taxpayer knowledge

\begin{tabular}{|l|ll|}
\hline Tax knowledge & Tax agents & Taxpayers \\
\hline Not knowledgeable & 1 & 12 \\
Somewhat knowledgeable & 44 & 49 \\
Knowledgeable & 35 & 19 \\
Very knowledgeable & 1 & 0 \\
\hline \hline Total & 81 & 80 \\
\hline
\end{tabular}

When asked what are the most likely reasons leading a taxpayer to use a tax agent, the most frequent answer from URA staff is that the tax system is too complex for taxpayers to deal with on their own (42.86\%). This is followed by wanting to adequately respond to a compliance query $(36.51 \%)$, with only 7.94 per cent answering that taxpayers are looking for tax planning. These answers are coherent with those to the questions of which tax agent services are most frequently requested by taxpayers. In this case, preparation and filing of tax returns is the most frequent answer $(38.27 \%)$, followed by preparation and auditing of financial accounts (30.86\%), and representing their clients before the URA (23.46\%). Overall, 
54.2 per cent of surveyed staff either agree or strongly agree that use of tax agents is an unavoidable consequence of a tax system strongly reliant on self-assessment. No significant difference emerges between opinions of staff in pre- and post-filing offices for any of the above answers. These findings resonate with another work that flagged the overall complexity of the Ugandan tax system (Waiswa et al. 2020), with studies indicating that a general willingness to comply with their obligation is the prevailing reason for taxpayers to hire professional tax agents (Hite et al. 1992; Tan 1999; Lubbe and Nienaber 2012), and that tax agents are relevant in URA-taxpayers interactions (Mayega et al. 2019).

More questions were asked to obtain a better picture of these latter interactions. Almost 70 per cent of survey respondents agreed that taxpayers are not confident in responding to queries from the URA on their own, which probably explains why 72.8 per cent of staff think that tax agents do not allow their clients to interface with the URA on their own. However, 43.2 per cent of URA staff also find it either difficult or very difficult to solve compliance issues without the involvement of tax agents (against $40.7 \%$ who find it easy or very easy). Taken together, these answers imply that tax agents acting as intermediaries between URA and taxpayers is convenient for both parties. Hence, tax agent involvement might have more to do with the complexity of the Ugandan tax system - or with perceptions of potential unfairness from URA officials - than with a desire from tax agents to maintain complete control over their clients' tax issues.

A final set of questions aimed to understand the impact of tax agents on returns' quality and compliance risk. The vast majority of URA staff think that use of tax agents does sometimes increase the quality of returns $(77.2 \%)$, with another 19 per cent stating that it always does so. The above is coherent with the fact that 29.1 per cent of respondents maintain that returns completed by tax agents still have computational mistakes, against 43 per cent that disagree with the statement. Returns prepared by tax agents are still considered risky from a compliance point of view by 36.25 per cent of surveyed staff, although 62.5 per cent find them less risky than those self-prepared. Self-prepared returns are considered risky by 76.5 per cent of respondents, and less risky than those submitted with an agent only by 22.2 per cent. It seems that, despite a somewhat mixed opinion on tax agents' preparedness, staff from the URA think that their use also contributes to improving the overall quality of returns submitted. This is confirmed by the fact that 43.2 per cent of respondents agreed that returns prepared by agents lead to less audit adjustments.

\subsection{Survey of tax agents}

The questionnaire submitted to tax agents aimed to gather information about the market in which URA-accredited tax agents operate, and the type of services they more often provide to their clients. The 'accredited' qualification is relevant, as there might be a variety of other actors in the Ugandan agents' market who have not yet sought accreditation from the URA, and who might exhibit different characteristics than those surveyed at the workshop. Similarly to the previous section, answers to particular questions lent themselves to test if significant systematic differences could be individuated across different categories of agents, such as self-employed or employees, and those with or without a professional association. ${ }^{14}$

First, almost 60 per cent of the 204 tax agents who took part in the URA workshops were self-employed, with the remainder working as employees. Given the registration requirements discussed in section 3 , it is not surprising to find that only 18 did not possess a university degree, with an undergraduate degree being the most common qualification (136

As in the previous section, systematic differences across ordinal variables have been tested with Mann-Whitney test and differences across categorical variables have been tested through Fisher's exact test, while differences across percentages with t-tests. 
respondents). Slightly more than half of the respondents (56.4\%) also have some form of professional association, with the Institute of Certified Public Accountant of Uganda being the most common one (78.3\% of those with an affiliation). The relative majority (37.2\%) first sought accreditation for 2018 - the first year TARC ran background checks - while another 35.1 per cent attempted to register after the Tax Procedures Code Act was passed in 2014. Moreover, 27.7 per cent claimed to have tried even before that - predominantly selfemployed tax agents. The majority of tax agents meets their clients more than once a month $(62.2 \%)$, around a quarter once a month $(22.9 \%)$, while there are also some for whom tax consultancy happens less frequently - every three months $(6.4 \%)$ or once a year $(8.5 \%)$.

Coming to the characteristics of their clients, the average share of incorporated clients $(68.9 \%)$ is much higher than individual clients $(29.6 \%)$, with only 19.9 per cent of respondents having a majority of individual clients. The use of tax agents seems to happen across all taxpayers' sizes, with small taxpayers representing on average almost half of tax agents' clients (46.4\%), and medium taxpayers around another third (30.3\%). Agents for whom incorporated clients are the majority are also more likely to have a majority of clients qualifying as medium or large taxpayers. No other significant difference in client characteristics was found across any other tax agent characteristic. While the above does not provide any indication of the prevalence of use of tax agents, it provides some evidence that the phenomenon has some relevance, as clients fall in all taxpayer categories both by size and incorporation status.

Table 3 Size of client of tax agents

\begin{tabular}{|l|ll|}
\hline & Average & No clients in category \\
\hline Micro taxpayers & $14.61 \%$ & $36.06 \%$ \\
Small taxpayers & $46.42 \%$ & $4.92 \%$ \\
Medium taxpayers & $30.25 \%$ & $15.3 \%$ \\
Large taxpayers & $8.72 \%$ & $51.37 \%$ \\
\hline
\end{tabular}

With regard to the most frequently requested services, about half of respondents $(50.4 \%)$ did not provide the ranking requested in the questionnaire (most frequent, $2^{\text {nd }}$ most frequent, $3^{\text {rd }}$ most frequent), but instead ticked all of those that were frequently requested. These responses still provide a useful indication of the type of services frequently provided, even if they do not technically represent a valid answer to the question. We have therefore decided to present both the valid and non-valid answers, in order to give the most complete picture possible. Table 4 presents the valid ranking of available answers. Preparation and auditing of accounts is generally one of the most requested services, as is the preparation and filing of returns. Representation before the URA and determination of tax liability, although not frequently the most requested service, are also functions that agents regularly perform for their clients. The unranked answers, presented in Table 5, show a very similar pattern. Preparation and filing of returns is the most frequently selected service, followed by representation in front of the URA and preparation or auditing of accounts. No significant difference in requested services could be individuated depending on tax agent characteristics. 
Table 4 Frequency of service provision, ranked answers

\begin{tabular}{|l|l|l|l|}
\hline Service & Most frequent & 2nd & 3rd \\
\hline \hline Preparation and filing of returns & $54.64 \%$ & $30.43 \%$ & $6.59 \%$ \\
Preparation or auditing of account & $27.84 \%$ & $27.17 \%$ & $9.89 \%$ \\
Representation before the URA & $6.19 \%$ & $20.65 \%$ & $38.46 \%$ \\
Determination of tax liability & $6.19 \%$ & $10.87 \%$ & $17.58 \%$ \\
Interpreting legislation & $2.06 \%$ & $6.52 \%$ & $16.48 \%$ \\
Consultation on legislative changes & $1.03 \%$ & $4.35 \%$ & $7.69 \%$ \\
Representation in court of law & $2.06 \%$ & $0.00 \%$ & $3.30 \%$ \\
\hline
\end{tabular}

Table 5 Frequently requested services, unranked answers

\begin{tabular}{|l|l|}
\hline Service & Frequency \\
\hline Preparation and filing of returns & $22.98 \%$ \\
Representation before the URA & $19.04 \%$ \\
Preparation or auditing of account & $16.41 \%$ \\
Determination of tax liability & $14.00 \%$ \\
Interpreting legislation & $12.04 \%$ \\
Consultation on legislative changes & $9.85 \%$ \\
Representation in court of law & $5.69 \%$ \\
\hline
\end{tabular}

We also asked tax agents what they thought were the most frequent reasons for their clients engaging their services. As with the previous case, a significant share of respondents (43.04\%) did not provide the ranking as requested but simply ticked all those that applied, and once again we present both valid and non-valid answers. Table 6 presents the ranked answers. As the table shows, the three most frequent answers are lack of tax knowledge, the desire to submit error-free returns, and the complexity of tax laws. All these answers seem to confirm that a general willingness to comply with tax legislation is a more important incentive to seek advice from an agent than reduction of tax liability, which is only mentioned by a minority of respondents. As before, the frequency of unranked answers closely follows that of ranked ones (Table 5).

Table 6 Frequency of reasons for being hired, ranked answers

\begin{tabular}{|l|l|l|l|}
\hline Reason to hire & Most frequent & 2nd & 3rd \\
\hline \hline Lack of tax knowledge & $64.08 \%$ & $11.46 \%$ & $4.60 \%$ \\
Decreasing chances of errors in returns & $12.62 \%$ & $29.17 \%$ & $27.59 \%$ \\
Complexity of tax law & $8.74 \%$ & $25.00 \%$ & $12.64 \%$ \\
External opinion on tax matter & $4.85 \%$ & $8.33 \%$ & $19.54 \%$ \\
Reduction of liability & $4.85 \%$ & $11.46 \%$ & $13.79 \%$ \\
Cost effectiveness of agent service & $4.85 \%$ & $9.38 \%$ & $8.05 \%$ \\
Reduction of audit probability & $0.00 \%$ & $5.21 \%$ & $13.79 \%$ \\
\hline
\end{tabular}


Table 7 Frequent reasons for being hired, unranked answers

\begin{tabular}{|l|l|}
\hline Reason to hire & Frequency \\
\hline \hline Lack of internal tax knowledge & $22.84 \%$ \\
Decreases chances of errors in returns & $19.54 \%$ \\
Complexity of tax law & $13.96 \%$ \\
External opinion on tax matter & $12.94 \%$ \\
Cost effectiveness of agent service & $11.93 \%$ \\
Reduction of audit probability & $10.66 \%$ \\
Reduction of liability & $8.12 \%$ \\
\hline
\end{tabular}

Pulling together the evidence from the last two questions, it seems that Ugandan taxpayers mostly refer to their tax agents to ensure that they are properly understanding and complying with their tax obligations, a finding that resonates with the literature for HICs (Hite et al. 1992; Tan 1999; Stephenson 2007, 2010; Lubbe and Nienaber 2012). While reducing liability is requested, it is a much less frequent reason to engage tax agents, again resonating with findings in the literature (Sakurai and Braithwaite 2003). Furthermore, this provides further evidence of the fact that the Ugandan tax system remains complex to understand for many taxpayers, and that there is further scope to work on outreach activities (Waiswa et al. 2020).

Agents were also asked if they believe that their services led to an increase, a decrease, or had no impact on their clients' tax liability, and more than three-quarters of respondents stated that it led to an increase $(76.57 \%)$. This answer could be due to two different factors tax agents were responding to the questionnaire during a training session run by the URA, which might have had an impact on the picture they wanted to provide. Alternatively, the Ugandan tax system might not provide much room for ambiguity, and tax agents might have resolved easy-to-detect non-compliance that their clients might have previously included in their returns. Considering the frequency with which the complexity of the tax system is highlighted, the first reason seems more likely than the second, but this will remain impossible to quantitatively verify until the e-Tax system is amended to allow the identification of agents submitting returns.

Around three-quarters of tax agents had clients subjected to audits (72.5\%), with 20 per cent stating that this happens often or very often. The latter finding is explained by comments made in some of the URA staff responses, which revealed that if a few returns prepared by the same agent were found to have similar discrepancies, then all returns prepared by that agent would be audited - a perfectly logical approach from a compliance risk perspective. Somehow unsurprisingly, almost all (98.04\%) agents thought that their services helped their clients increase their understanding of tax matters. The majority of agents (63.13\%) indicated that their clients were somewhat knowledgeable about tax law, and more than a quarter that they are knowledgeable (28.79\%). Finally, there is an almost even split between agents indicating that their clients would not feel confident in responding to a query from the URA without consulting them first (51.74\%), and those indicating instead that their clients would be $(48.26 \%)$ - corroborating the answers provided by URA staff.

\section{Conclusion}

Over the last 40 years there has been an increased focus on the role that tax agents play in ensuring or deterring compliance with tax obligations. This body of work provides enough evidence to derive a series of conclusions. First, it is accepted that tax agents ensure that 
their clients follow unambiguous tax rules to the letter, but they also exploit ambiguities in tax laws to minimise liabilities when possible. The degree to which they are successful in doing so depends on their qualifications, as agents who can shield their clients from penalties with limited professional consequences are more likely to take more aggressive stances. From the taxpayer point of view, reducing the risk of penalties and probability of audit seem to be the main reasons to employ tax agents. Although decreasing tax liabilities is also a soughtafter service, there is evidence that taxpayers prefer conservative over aggressive advice on reducing liability in the majority of cases. However, those who have a greater risk appetite generally find tax agents who can satisfy their requests, although the latter may draw a line as to how much non-compliance they will support.

The majority of the above evidence has been obtained from high-income countries, with only a few studies assessing the role of tax agents in upper-middle-income contexts. Given that tax systems in low-income countries tend to exhibit significant differences from those of highand upper-middle-income ones, it is worth investigating if the use of tax agents is as widespread, and if their effect is comparable. This is especially relevant given that resolving a variety of non-compliance issues is often one of the main obstacles to increasing domestic resource mobilisation in those countries.

We have presented some initial evidence on the characteristics of the market for tax agents in Uganda, how the URA perceives their role, and which regulative approach has been taken, by means of two surveys and various in-depth interviews. To the best of our knowledge, this is the first time that this topic has been explored in a lower-income country setting. While our surveys are not likely to be representative, they provide initial support to the hypothesis that tax agents play a similar role in the Ugandan context as they do in highincome country settings.

Tax agents provide their services to all types of taxpayers - both corporations and individuals, whether they are micro, small, medium or large taxpayers. Their clients seem to seek their services due to difficulties with both understanding and complying with their tax obligations - reduction of liabilities is generally a much less important reason to seek the services of an agents. Accordingly, their most requested services are preparation and filing of returns, as well as preparation and auditing of financial accounts, with tax minimisation being a much less frequent request.

Staff from the URA seem to have mixed opinions on the usefulness of tax agents. They consider them more knowledgeable than taxpayers, but not at the level that one would expect. While they recognise that agents generally improve the quality of tax returns, around a third of respondents flagged that they also make computational mistakes, and agentprepared returns are often filed late. Regardless, they still consider returns prepared by tax agents less risky than those self-prepared by taxpayers, and they recognise that audit adjustments are smaller when tax agents are in charge of return preparation.

Our results have a series of policy implications, as they demonstrate that a variety of different taxpayer categories use agents' services, so that interacting with agents could be a further strategy for the URA to reach taxpayers. This interaction could go both ways - agents could relay to the URA which provisions are harder for taxpayers to cope with, and the URA relay to agents its position on more ambiguous tax rulings. Interviews with the Tax Agent Regulation Committee (TARC) revealed the complexity of setting up a regulated framework for the accreditation of tax agents, and some potential issues with the current regulation of entry-level requirements and who should be using a tax agent. 
Some reform of the regulations is currently taking place. The TARC has drafted a policy proposal to be included in the 2021/2022 tax policy amendments, prescribing penalties for agents providing assistance to taxpayers without formal accreditation, and for agents influencing taxpayers into acts of malpractice. As the literature shows that regulation of agents has an impact on their service provision, these reforms could limit particular detrimental behaviour from agents. However, other weaknesses of the current regulation of agents, especially their required qualifications, seem not to have been addressed. Similarly, a system is being set up to enable tracking of information relating to the performance of tax agents, who will from now on file returns on their clients' behalf from a separate account. Thanks to this development, it will soon be possible to rely on tax returns to verify some of the claims made by both URA staff and agents themselves. These include the frequency of mistakes in agent-prepared returns, as well as their relative compliance risk, audit adjustment, frequency of late filing and differences in liability. It could also be of interest to obtain information on the use of tax agents from taxpayers themselves. This could not be covered in the present study due to pandemic restrictions in place when the research was conducted. 


\section{References}

Allingham, M. and Sandmo, A. (1972) 'Income Tax Evasion: A Theoretical Analysis', Journal of Public Economics 1: 323-338

Ayres, F., Jackson, B. and Hite, P. (1989) 'The Economic Benefits of Regulation: Evidence from Professional Tax Preparers', The Accounting Review 64(2): 300-312

Barr, N., James, S. and Prest, A. (1977) Self-assessment for income tax, London: Heinemann Educational for the Institute of Chartered Accountants in England and Wales and the Institute for Fiscal Studies

Blumenthal, M. and Slemrod, J. (1992) 'The compliance cost of the U.S. Individual Income Tax System: a Second Look After Tax Reform', National Tax Journal 45(2): 185-202

Braithwaite, V. (2001) 'The Community Hopes, Fears and Actions Survey: Goals and Measures', Centre for Tax System Integrity Working Paper 2

Chetty, R. and Saez, E. (2013) 'Teaching the Tax Code: Earnings Responses to an Experiment with EITC Recipients', American Economic Journal: Applied Economics 5(1): 1-31

Christensen, A. (1992), 'Evaluation of Tax Services: A Client and Preparer Perspective', The Journal of the American Taxation Association 14(2): 60-87

Cloyd, C. and Spilker, B. (1999) 'The Influence of Client Preferences on Tax Professionals' Search for Judicial Precedents, Subsequent Judgments and Recommendations', The Accounting Review 74(3): 299-322

Eichfelder, S. and Schorn, M. (2012) 'Tax Compliance Costs: A Business-Administration Perspective', FinanzArchiv / Public Finance Analysis 68(2): 191-230

Erard, B. (1993) 'Taxation with representation. An analysis of the role of tax practitioners in tax compliance', Journal of Public Economics 52:163-197

Forest, A. and Sheffrin, S. (2002) 'Complexity and Compliance: An Empirical Investigation', National Tax Journal 55(1): 75-88

Frecknall-Huges, J. and Kirchler, E. (2015) 'Towards a General Theory of Tax Practice', Social and Legal Studies 24(2): 289-315

and Moizer, P. (2015) 'Assessing the quality of services provided by UK tax practitioners', eJournal of Tax Research 13(1): 51-75

Fleischman, G. and Stephenson, T. (2012) 'Client Variables Associated with Four Key Determinants of Demand for Tax Preparer Services: an Exploratory Study', Accounting Horizons 26(3): 417-437

Gupta, R. (2015) 'Relational impact of tax practitioners' behavioural interaction and service satisfaction: Evidence from New Zealand', eJournal of Tax Research 13(1): 76-107 
Hasseldine, J., Holland, K. and van der Rijt, P. (2011) 'The market for corporate tax knowledge', Critical Perspectives on Accounting 22: 39-52

Hite, P., Stock, T. and Cloyd. C. (1992) 'Reasons for Preparer Usage by Small Business Owners: How Compliant Are They?', The National Public Accountant 37(2): 20-26

Isa, K., Yussof, S. and Mohdali, R. (2014) 'The role of tax agents in sustaining the Malaysian tax system', Procedia - Social and Behavioral Sciences 164: 366-371

Jackson, B. and Milliron, V. (1989) 'Tax Agents: Government Agents or Client Advocates: A Response to the IRS's Survey on Tax Agents Attitudes', Journal of Accountancy 17: 76-81 $-\frac{}{338}$ and Toy, D. (1988) 'Tax Practitioners and the Government', Tax Notes 41: 333-

James, S. and Alley, C. (2004) Tax Compliance, Self-Assessment and Tax Administration', Journal of Financial and Management in Public Services 2: 27-42

Kangave, J., Byrne, K. and Karangwa, J. (2020) Tax Compliance of Wealthy Individuals in Rwanda, ICTD Working Paper 109, Brighton: Institute of Development Studies

_ Nakato, S., Waiswa, R., Nalukwago M. and Zzimbe, P. (2018) What Can We Learn from the Uganda Revenue Authority's Approach to Taxing High Net Worth Individuals?, ICTD Working Paper 72, Brighton: Institute of Development Studies

—— - and Zzimbe, P. (2016) Boosting Revenue Collection through Taxing High Net Worth Individuals: The Case of Uganda, ICTD Working Paper 45, Brighton: Instistute of Development Studies

Kaplan, S., Reckers, P., West, S. and Boyd, J. (1988) 'An Examination of Tax Reporting Recommendations of Professional Tax Preparers', Journal of Economic Psychology 9: 427-433

Klepper, S., Mazur, M. and Nagin, D. (1991) 'Expert Intermediaries and Legal Compliance: The Case of Tax Agents', The Journal of Law and Economics 34(1): 205-229

— and Nagin, D. (1989) 'The Role of Tax Preparers in Tax Compliance', Policy Science 22(2): 167-194

Long, J. and Caudill, S. (1987) 'The Usage and Benefits of Paid Tax Return Preparation', National Tax Journal 40(1): 35-46

Lubbe, M. and Nienaber, G. (2012) 'Do South African Small Businesses Prefer Conservative Tax Advice to Aggressive Tax Advice', International Business and Economics Research Journal 11(6): 697-712

MOFPED (2019) Domestic Revenue Mobilisation Strategy - 2019/20-2023/24, Ugandan Ministry of Finance, Planning and Economic Development

Mayega, J., Ssuuna, R., Mubajje, M., Nalukwago, M. and Muwonge, L. (2019) How Clean is Our Taxpayer Register? Data Management in the Uganda Revenue Authority, ICTD African Tax Administration Paper 12, Brighton: Institute of Development Studies 
McKerchar, M., Bloomquist, K. and Leviner, S. (2008) 'Improving the quality of services offered by tax agents: can regulation assist?', Australian Tax Forum 23: 399-425

Mearns, M. and Braithwaite, V. (2001) The Community Hopes, Fears and Actions Survey: Survey method, sample representativeness and data quality, Centre for Tax System Integrity working paper no. 4

Moore, M. (2020) What is Wrong with African Tax Administration?, ICTD Working Paper 111, Brighton: Institute of Development Studies

— and Prichard, W. (2017) How Can Governments of Low-Income Countries Collect More Tax Revenue?, ICTD Working Paper 70, Brighton: Institute of Development Studies

Mulligan, E. and Oats, L. (2016) 'Tax professionals at work in the Silicon Valley', Accounting Organizations and Society 52: 63-76

Murphy, K. (2003) 'Aggressive tax planning: Differentiating those playing the game from those who don't', Journal of Economic Psychology 25: 307-329

- (2002) Procedural Justice and the Australian Taxation Office: A study of tax scheme investors, Centre for Tax System Integrity Working Paper 35, The Australian National University

and Byng, K. (2002) Preliminary Findings from 'The Australian Tax System Survey of Tax Scheme Investors', Centre for Tax System Integrity Working Paper 40, The Australian National University

Newberry, K., Reckers, P. and Wyndelts, R. (1993) 'An examination of tax practitioner decisions: The role of preparer sanctions and framing effects associated with client condition', Journal of Economic Psychology 14: 439-452

Niemirowski, P., Baldwin, S. and Wearing, A. (2003) 'Tax related behaviours, beliefs, attitudes and values and taxpayer compliance in Australia', Journal of Australian Taxation 6(1): 132-165

OECD (2008) Study into the Role of Tax Intermediaries, Paris: Organisation for Economic Cooperation and Development

Remeur, C. (2018) Tax transparency for intermediaries, EU Legislation in Progress Briefing, European Parliament Research Service

Roxan, I., Kamath, S., De Groen, W. (2017) Rules on independence and responsibility regarding auditing, tax advice, accountancy, account certification services and legal services, Study for the PANA Committee, European Parliament

Sakurai, Y. and Braithwaite, V. (2003) 'Taxpayers' Perceptions of Practitioners: Finding One Who Is Effective and Does the Right Thing?', Journal of Business Ethics 46(4): 375387

Sapiei, N. and Kasipillai, J. (2014) 'Tax Agents Perceptions of the Corporate Taxpayers' Compliance Costs under the Self-assessment System', International Journal of Business and Management 2(3): 92-109 
Schisler, D. (1994) 'An Experimental Examination of Factors Affecting Tax Preparers' Aggressiveness - A Prospect Theory Approach', The Journal of the American Taxation Association 16(2): 124-142

Sinnasamy, P., Bidin, Z. and Ismail, S. (2015) 'A Proposed Model of Non-Compliance Behaviour on Excise Duty: A Moderating Effect of Tax Agents', Procedia - Social and Behavioral Sciences 211: 299-305

Slemrod, J. (2019) 'Tax Compliance and Enforcement', Journal of Economic Literature 57(4): 904-954

_ (1989) 'The Return to Tax Simplification: an Econometric Analysis', Public Finance Quarterly 17(1): 3-28

— and Sorum, N. (1984) 'The compliance cost of the U.S. individual income tax system', National Tax Journal 37: 361-370

and Venkatesh, V. (2002) The Income Tax Compliance Cost of Large and Mid-Size Businesses, Ross School of Business Working Paper Series No. 914, University of Michigan

Stephenson, T. (2010) 'Measuring taxpayers' motivation to hire tax agents: the development of a four-construct scale', Advances in Taxation 19: 95-121

_ (2007) 'Do Clients Share Preparers' Self-Assessment of the Extent to Which they Advocate for Their Clients?', Accounting Horizons 21(4): 411-422

— Fleischman, G. and Peterson, M. (2017) 'Demand for tax-preparation services: an exploratory examination of client versus tax-preparer expectation gaps', Advances in Taxation 24: 203-236

Tan, L. (2014) 'Understanding the tax practitioner-client relationship: Using a role theory framework', Procedia - Social and Behavioral Sciences 164: 242-247

(1999) 'Taxpayers' preference for type of advice from tax practitioner: A preliminary Examination', Journal of Economic Psychology 20: 431-447

Teviotdale, W. and Thompson, S. (1999) 'Self-assessment: revenue authorities v. taxpayers: a state of conflict?', British Tax Review 4: 272-283

Thuronyi, V. and Vanistendael, F. (1996) 'Regulation of Tax Professionals', in V. Thuronyi (ed.) Tax Law Design and Drafting Volume 1, International Monetary Fund

Waiswa, R., Akol, D. and Isingoma, M. (2020) Who can make Ugandan taxpayers more compliant?, ICTD African Tax Administration Paper 18, Brighton: Institute of Development Studies

Zwick, E. (2018) The Costs of Corporate Tax Complexity, NBER Working Paper Series 24382, National Bureau of Economic Research 